Article

\title{
Preparation and Characterization of Zinc Materials Prepared by Powder Metallurgy
}

\author{
Michaela Krystýnová ${ }^{1, *}$, Pavel Doležal ${ }^{1,2}$, Stanislava Fintová ${ }^{1,3}$, Matěj Březina ${ }^{1}$, Josef Zapletal ${ }^{2}$ \\ and Jaromír Wasserbauer ${ }^{1}$ \\ 1 Materials Research Centre, Faculty of Chemistry, Brno University of Technology, Purkyňova 464/118, \\ 61200 Brno, Czech Republic; dolezal@fme.vutbr.cz (P.D.); fintova@ipm.cz (S.F.); \\ xcbrezinam@fch.vut.cz (M.B.); wasserbauer@fch.vut.cz (J.W.) \\ 2 Institute of Materials Science and Engineering, Faculty of Mechanical Engineering, \\ Brno University of Technology, Technická 2896/2, 61669 Brno, Czech Republic; zapletal@fme.vutbr.cz \\ 3 Institute of Physics of Materials Academy of Sciences of the Czech Republic, Žižkova 22, 61662 Brno, \\ Czech Republic \\ * Correspondence: xckrystynovam@fch.vut.cz; Tel.: +420-541-149-469
}

Received: 30 August 2017; Accepted: 22 September 2017; Published: 27 September 2017

\begin{abstract}
The use of zinc-based materials as biodegradable materials for medical purposes is offered as a possible alternative to corrosion-less resistant magnesium-based materials. Zinc powders with two different particle sizes $(7.5 \mu \mathrm{m}$ and $150 \mu \mathrm{m})$ were processed by the methods of powder metallurgy: cold pressing, cold pressing followed by sintering and hot pressing. The microstructure of prepared materials was evaluated in terms of light optical microscopy, and the mechanical properties were analyzed with Vickers microhardness testing and three-point bend testing. Fractographic analysis of broken samples was performed with scanning electron microscopy. Particle size was shown to have a significant effect on compacts mechanical properties. The deformability of $7.5 \mu \mathrm{m}$ particle size powder was improved by increased temperature during the processing, while in the case of larger powder, no significant influence of temperature was observed. Bending properties of prepared materials were positively influenced by elevated temperature during processing and correspond to the increasing compacting pressures. Better properties were achieved for pure zinc prepared from $150 \mu \mathrm{m}$ particle size powder compared to materials prepared from $7.5 \mu \mathrm{m}$ particle size powder.
\end{abstract}

Keywords: powder metallurgy; zinc; cold pressing; sintering; hot pressing; mechanical properties

\section{Introduction}

In the field of biodegradable metal materials, magnesium and its alloys are the most studied [1-6]. Due to their suitable mechanical properties such as high specific strength, stiffness and damping ability, they are suitable materials for the preparation of bone implants [1-7]. Because of its low corrosion resistance and therefore difficult degradation control, magnesium is not used in its pure state, but alloyed. Commercial magnesium alloys are not primarily designed for medical applications, but some studies on the biomedical purpose of these alloys were done before, showing good corrosion behavior and biocompatibility [8,9]. For medical purposes, magnesium alloys with calcium, zinc, rare earth elements or manganese are being considered [10-13]. Due to the low density of calcium, these alloys have a similar density as a natural bone. In addition, $\mathrm{Ca}^{2+}$ ions are beneficial for human bones, and $\mathrm{Mg}^{2+}$ ions support the function of $\mathrm{Ca}^{2+}$ ions and generally the treatment of injury $[11,14,15]$.

Zinc has been considered, in the field of biomedical applications, a suitable alloying element for magnesium alloys in terms of improving corrosion resistance and enhancement of mechanical properties $[10,16,17]$. Considering zinc is a nobler metal than magnesium and zinc is also biocompatible, it can be a suitable biodegradable material [16-18]. Zinc is a nutritionally-essential element in the 
human body; approximately $85 \%$ of $\mathrm{Zn}$ in the human body can be found in bone and muscle. It is an integral part of the structure of macromolecules and enzymes, and it participates in a large number of enzymatic reactions. The human zinc requirement for adult males is $10-15 \mathrm{mg} /$ day (upper limit $40 \mathrm{mg} /$ day) $[19,20]$. The potential for systemic toxicity of metallic zinc should be nonexistent due to the rapid transport of ionic zinc in living tissue. Moreover, higher consumption (up to $100 \mathrm{mg} / \mathrm{day}$ ) of zinc is considered non-toxic. However, more detailed cytotoxicity tests must be carried out in the future $[15,21-23]$.

Based on its positive effect on the human body, zinc can be considered a suitable base material for the preparation of biodegradable materials. There are only a few works dealing with the use of zinc alloys for biomedical applications. In the case of pure zinc, there is just one article [22] dealing with the applicability of zinc as a bioabsorbable cardiac stent material, according to the author's knowledge. The authors in [22] demonstrated the biocorrosion behavior of zinc by a series of four wire samples implanted in the abdominal aorta of Sprague-Dawley rat for 1.5, 3, 4.5 and 6 months. Results show that zinc corrosion is slower than the corrosion of magnesium and its alloys [24,25]. Zinc implants stay almost intact for approximately four months, and then, corrosion subsequently accelerates. Corrosion products of zinc are formed from zinc oxide and zinc carbonate. Due to the slow corrosion of zinc, there is sufficient time to exclude hydrogen resulting from the corrosion process. That is both the main difference and an advantage over magnesium [21]. However, no mechanical tests results were provided in this work.

Generally, the mechanical properties of zinc are relatively low. The modulus of compressive elasticity of commercially pure zinc is not listed as an exact value because there is no region of strict proportionality in the compressive stress-strain curve. Therefore, this value was determined in the range from 70-140 GPa [25]. The Vickers hardness of this material is $30 \mathrm{HV}$. The tensile strength of wrought pure zinc is in the range of 120-150 MPa, depending on the direction of rolling [26]. The tensile strength of cast pure zinc is very low with the value approximately $25 \mathrm{MPa}$ [17]. Another article dealing with mechanical properties of zinc showed that applying hot extrusion $\left(300^{\circ} \mathrm{C}\right.$, extrusion ratio $10: 1,2 \mathrm{~mm} / \mathrm{min}$ ) can enhance the ultimate tensile strength to a value of approximately $100 \mathrm{MPa}$ and a Vickers hardness to 44 HV5 [27] and, in [28], to approximately $110 \mathrm{MPa}$ for hot extruded pure zinc material $\left(250{ }^{\circ} \mathrm{C}, 14: 1\right)$. Due to the poor mechanical properties, alloying of zinc is a suitable solution. As alloying elements, mostly magnesium [17,27,29], aluminum [30,31] and silver [28] were studied.

Alloying zinc with aluminum provides substantial enhancement of the mechanical properties. That is due to the presence of Al-Zn solid solution and the volume fraction of the lamellar microconstituents from the monotectoid reaction acting as potential barriers for dislocation motion. With an addition of $5.5 \mathrm{wt} \%$ of aluminum, the tensile strength of material prepared by hot rolling at $350{ }^{\circ} \mathrm{C}$ reaches the value of approximately $308 \mathrm{MPa}$ and a yield strength of approximately $240 \mathrm{MPa}$ [30]. However, the use of $\mathrm{Zn}-\mathrm{Al}$ alloys in medicine is still limited, because of the uncertainty regarding the toxicity of aluminum. Although, the toxicity of aluminum has never been sufficiently proven [30], its connection to neurological disorders is still discussed in the literature [32]. Furthermore, the corrosion resistance of $\mathrm{Zn}-\mathrm{Al}$ alloys tended to be lower compared to high purity zinc due to the intergranular corrosion. Moreover, volume expansion associated with the formation of corrosion products led to cracking and fragmentation of implants [30]. Another alloying element with positive influence on mechanical properties and preserving biocompatibility is silver. With the addition of $7.0 \mathrm{wt} \%$ of $\mathrm{Ag}$, the ultimate tensile strength of the cast zinc alloy increased up to $287 \mathrm{MPa}$ [28]. Moreover, silver has been used in medicine for healing wounds, and it is used, in the form of nanoparticles, for the prevention of the adherence of bacteria to the surface of implants [33]. However, the presence of secondary phase particles in the $\mathrm{Zn}$-Ag alloys led to micro-galvanic corrosion because they act as anodes. Consequently, $\mathrm{Zn}-\mathrm{Ag}$ alloys have higher degradation rates in comparison with pure Zn [28].

Probably the most discussed alloying element of zinc-based biodegradable materials is magnesium. Because of the existence of the hard $\mathrm{Mg}_{2} \mathrm{Zn}_{11}$ intermetallic phase in the alloy structure, 
the value of the hardness increases with a higher content of magnesium up to the value of $200 \mathrm{HV}$ (cast alloy, $3 \mathrm{wt} \%$ of magnesium). With higher magnesium content (35-45 wt \% of magnesium), the hardness of the cast alloys can reach values of approximately 285-300 HV1 for $35 \mathrm{wt} \%$ of magnesium (depending on the cast product cooling rate and subsequent microstructure). The hardness increases because of the presence of another strengthening phase in the alloy microstructure $\left(\mathrm{MgZn}_{2}\right)$. With the higher content of magnesium in the alloy, the content of the $\mathrm{MgZn}_{2}$ phase decreases and the content of the $\mathrm{MgZn}$ and $\mathrm{Mg}_{7} \mathrm{Zn}_{3}$ phases increases. The hardness falls again due to decreasing content of $\mathrm{MgZn} \mathrm{n}_{2}$ to 255-280 HV1 for the alloy with $45 \mathrm{wt} \%$ of magnesium (depending on the cast product cooling rate and subsequent microstructure) [29]. However, the existence of brittle eutectic phases in alloys with the content of magnesium higher than $1 \mathrm{wt} \%$ has a negative effect on ultimate tensile strength. Ultimate tensile strength increases up to $150 \mathrm{MPa}(1 \mathrm{wt} \%$ of $\mathrm{Mg})$ and then decreases to the value of $30 \mathrm{MPa}$ ( 3 wt \% of $\mathrm{Mg}$ ). That is the same value as for pure zinc prepared by the same method. Furthermore, elongation of $\mathrm{Zn}-\mathrm{Mg}$ alloys reaches the highest value for the alloy with $1 \mathrm{wt} \%$ of magnesium [17]. Another article deals with an enhancement of mechanical properties with hot extrusion processing. Hot extruded alloy with $0.8 \mathrm{wt} \%$ of magnesium reaches the ultimate tensile strength of approximately $300 \mathrm{MPa}$ and a Vickers hardness of approximately $80 \mathrm{HV} 5$. With the content of $1.6 \mathrm{wt} \%$ of magnesium, hot extruded materials reach the ultimate tensile strength of approximately $360 \mathrm{MPa}$ and a Vickers hardness of approximately 97 HV5 [27].

Most of the available articles deal with the influence of alloying elements and their content on the mechanical properties and corrosion resistance of zinc-based materials prepared by casting or mechanical treatment of cast products. The influence of the preparation method and its parameters on mechanical properties is studied only marginally $[17,27-30]$.

This work deals with three different methods of preparation of zinc materials by powder metallurgy: cold pressing, cold pressing followed by sintering and hot pressing. According to the author's knowledge, there is no available publication related to the preparation of pure zinc by these methods. Besides the influence of the preparation method, this work also focuses on the influence of the particle size of the used powder materials on the resulting microstructure and mechanical properties.

\section{Materials and Methods}

For the experiment, two different zinc powders $(99.8 \%$ purity, $7.5 \mu \mathrm{m}$ and $150 \mu \mathrm{m}$ mean particle size provided by Goodfellow Cambridge Limited Company (Huntingdon, UK) were used. The smaller, $7.5 \mu \mathrm{m}$ particle size powder (Zn7.5) was prepared by the electrothermal process, and the larger, $150 \mu \mathrm{m}$ particle size powder (Zn150) was prepared by air atomization. In order to prevent material oxidation, manipulation with $\mathrm{Zn}$ powder was carried out in an inert atmosphere $\left(\mathrm{N}_{2}\right)$ in the glove box. The size and shape of metal powder particles were verified and analyzed by a Zeiss Evo LS 10 scanning electron microscope (SEM; Carl Zeiss Ltd., Cambridge, UK).

The particles of $\mathrm{Zn}$ powder with the declared particle size of $7.5 \mu \mathrm{m}$ had spherical shapes, and their size ranged from $1 \mu \mathrm{m}$ to a maximum value of $20 \mu \mathrm{m}$ (Figure 1a). The particles tended to clump. The smaller particles attached to the larger ones and created clusters. The particles of zinc powder with a declared particle size of $150 \mu \mathrm{m}$ were irregularly rod-shaped with a minor amount of round-shaped particles (Figure 1b). The SEM analysis of the powder showed that some particles in their largest dimension reached a size from $40-640 \mu \mathrm{m}$.

The purity of powders declared by the supplier was verified by EDS analysis. The larger content of oxygen, approximately $8.0 \pm 0.5 \mathrm{wt} \%$, was determined in Zn7.5 powder when compared to Zn150 powder, containing only $2.5 \pm 0.5 \mathrm{wt} \%$.

Experimental samples were processed in three ways: (i) By bidirectional cold pressing (CP), (ii) cold pressing followed by sintering (CP-S) and (iii) hot pressing (HP). A hollow cylindrical steel die with the inner diameter of $20 \mathrm{~mm}$ was used for zinc powders' compaction. Before it was filled with zinc, the die surface was carburized in order to prevent adhesion of the base powder material to the surface of the die. The pressing of the powders was carried out by the Zwick Z250 Allround-Line 
universal testing machine (Zwick GmbH \& Co.KG, Ulm, Germany) with a velocity of $2 \mathrm{~mm} / \mathrm{min}$. Pressures of 100, 200, 300, 400 and 500 MPa were used for prepared powders' compaction.

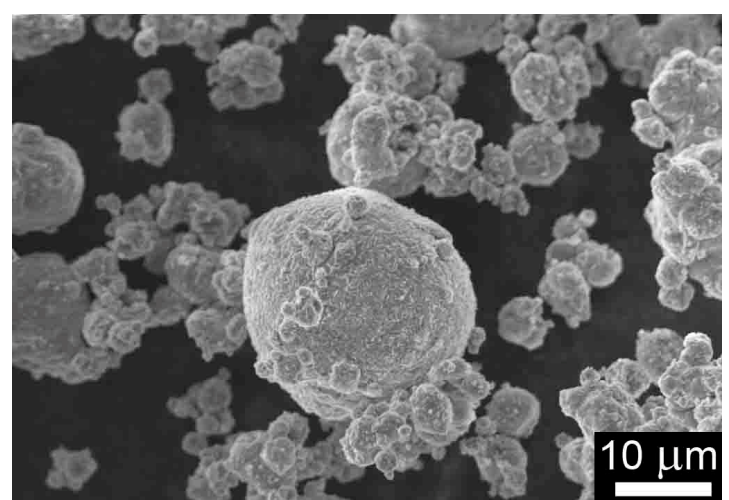

(a)

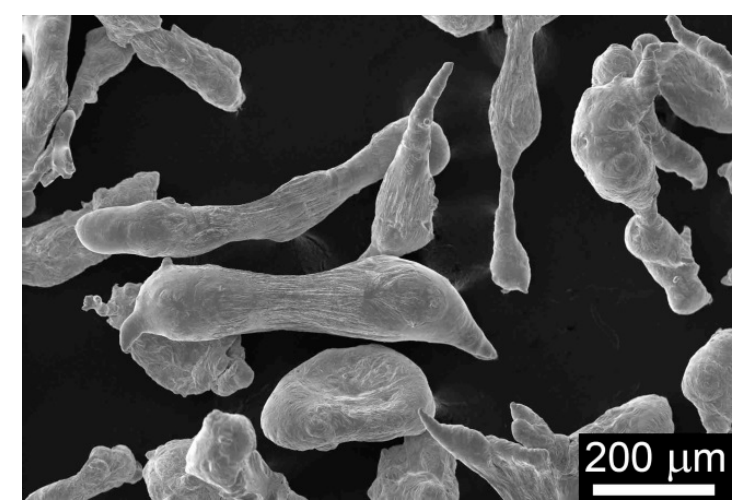

(b)

Figure 1. Zn particles, SEM (scanning electron microscope): (a) Mean particle size $7.5 \mu \mathrm{m}$; (b) mean particle size $150 \mu \mathrm{m}$.

For sintering, cold-pressed samples pressed under 100, 200, 300, 400 and $500 \mathrm{MPa}$ were used. Cold-pressed samples were inserted into glass vials and then filled with argon of purity 4.6 and sealed. The sintering of pressed powder was done for $1 \mathrm{~h}$ at a temperature of $400{ }^{\circ} \mathrm{C}$ in the laboratory furnace preheated to the required temperature.

Hot pressing was carried out for $1 \mathrm{~h}$ at a temperature of $400{ }^{\circ} \mathrm{C}$ under 100, 200, 300, 400 and $500 \mathrm{MPa}$. Prepared bulk materials were in the form of cylindrical tablets with a diameter of $20 \mathrm{~mm}$ and a height of $5 \mathrm{~mm}$.

Metallographic evaluation of prepared samples was performed in a conventional manner. Isopropanol was used as a lubricant and a rinse to prevent oxidation of the samples during grinding and polishing. For metallographic evaluation, the Zeiss Axio Z1M (Carl Zeiss AG, Oberkochen, Germany) inverted light optical microscope (OM) and Zeiss Evo LS 10 (Oxford Instruments, Abington, UK) were used. The microhardness of prepared samples was measured with the LM 248 at machine produced by LECO Company (Saint Joseph, MO, USA). The measurement was carried out in accordance with the ISO 6507-1 standard (Vickers method, applied load $25 \mathrm{~g}$ ) on 10 positions on the sample.

The 3-point bend test was carried out on the Zwick Z020 (Zwick GmbH \& Co.KG, Ulm, Germany) universal testing machine according to the ISO 7438 standard. One sample for each preparation condition was used for the 3-point bend test. Samples for testing were detracted from the central part of prepared tablets and ground up to $4 \mathrm{~mm} \times 4 \mathrm{~mm} \times 18 \mathrm{~mm}$ proportions with the support span of $16 \mathrm{~mm}$. Fractographic evaluation of the fracture surfaces of broken samples was performed by SEM. Documentation was carried out in the area of applied tensile stress.

\section{Results}

\subsection{Processed Material Analysis}

Microstructures of materials prepared from Zn7.5 applying minimal and maximal (100 and $500 \mathrm{MPa}$ ) compacting pressures are summarized in Figure 2. The results showed the low deformation ability of the Zn7.5 powder particles and an open porosity of materials prepared under the low compacting pressure of $100 \mathrm{MPa}$. The porosity of the samples compacted under $100 \mathrm{MPa}$ decreased with applying temperature. While in the case of $\mathrm{CP}$, quite a high level of porosity was observed, in the case of the CP-S sample, the porosity level decreased, and only very limited porosity was observed for the HP Zn7.5 powder sample. Low compacting pressure resulted also in low handling strength of samples, and falling off of individual particles during the metallographic sample preparation was 
observed (marked by arrows). The HP Zn7.5 powder sample microstructural analysis revealed small particle deformation during the bulk material processing, which was not observed in the case of $\mathrm{CP}$ and CP-S samples compacted under $100 \mathrm{MPa}$.

The microstructure of materials pressed under $500 \mathrm{MPa}$ shows much lower porosity than samples pressed under $100 \mathrm{MPa}$, considering the same processing conditions (Figure 2). Only small particles' deformation can be seen in the case of the CP sample compacted under $500 \mathrm{MPa}$ (Figure 2b); however, by the addition of temperature (CP-S and HP), the particles' deformation increased (Figure 2e,f).

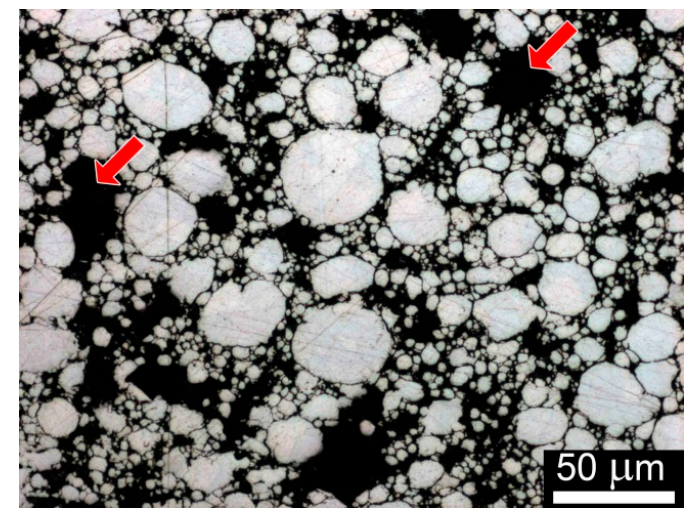

(a)

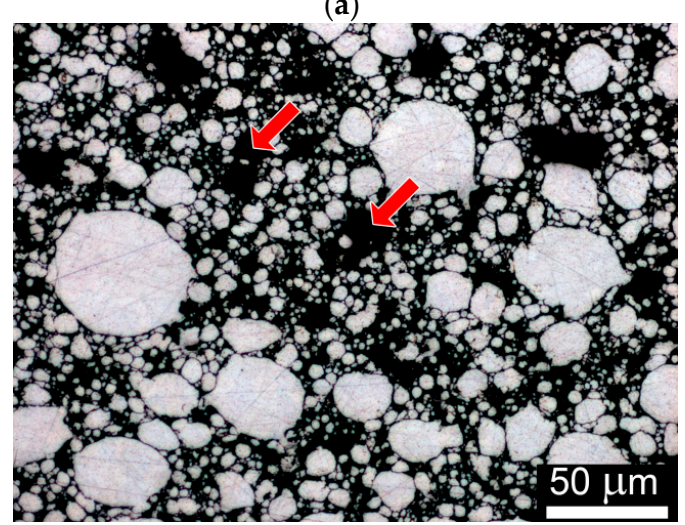

(c)

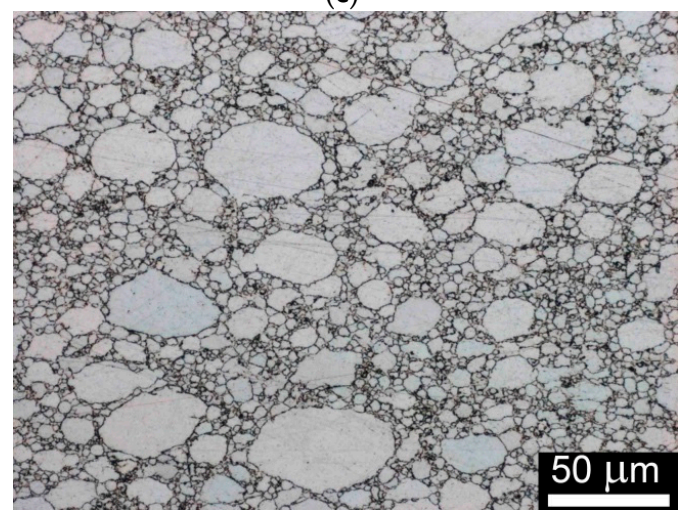

(e)

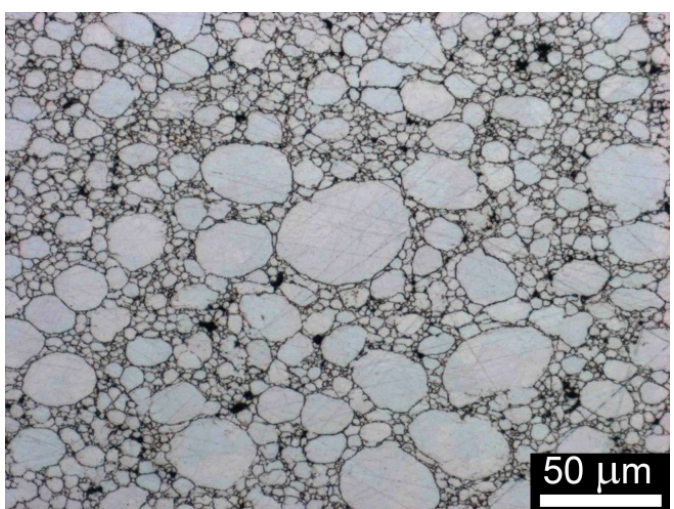

(b)

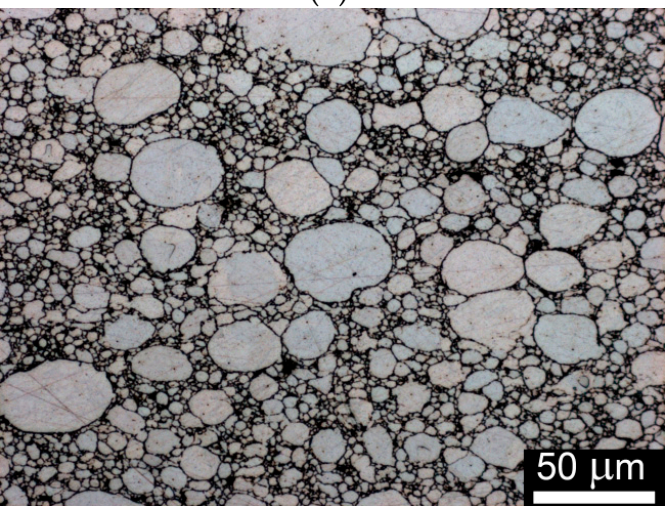

(d)

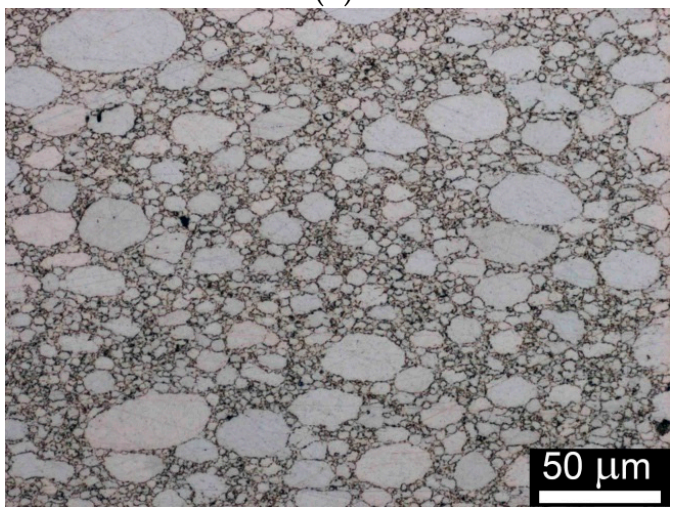

(f)

Figure 2. Microstructure of materials prepared from Zn7.5 powder, etched with $5 \%$ Nital, optical microscope (OM): (a) $100 \mathrm{MPa}, \mathrm{CP}$; (b) $500 \mathrm{MPa}, \mathrm{CP}$; (c) $100 \mathrm{MPa}, \mathrm{CP}-\mathrm{S}$; (d) $500 \mathrm{MPa}, \mathrm{CP}-\mathrm{S}$; (e) $100 \mathrm{MPa}$, $\mathrm{HP}$; (f) $500 \mathrm{MPa}$, HP (CP: Cold pressing; S: Sintering; HP: Hot pressing).

The microstructure of materials prepared from Zn150 powder under 100 and $500 \mathrm{MPa}$ compacting pressures is shown in Figure 3. In the case of material compacted under a pressure of $100 \mathrm{MPa}$, closed pores can be seen between the powder particles in the microstructure (Figure 3a). Even larger porosity 
can be seen in the CP-S sample's microstructure (Figure 3c), while the porosity is not visible in the case of the HP sample (Figure 3e). Compacting pressure of $500 \mathrm{MPa}$ resulted in a microstructure without defects for all used processing methods of Zn150 powder-based materials (Figure 3). Zn150 powder particles' deformation was observed for all the material processing methods and all the used compacting pressures. Particles deformation increased with the addition of temperature, i.e., larger particles' deformation was observed for material processed by CP-S and even larger for material processed by HP when compared to $\mathrm{CP}$ material. Larger particle deformation was observed for samples prepared under $500 \mathrm{MPa}$ compared to samples prepared under $100 \mathrm{MPa}$.

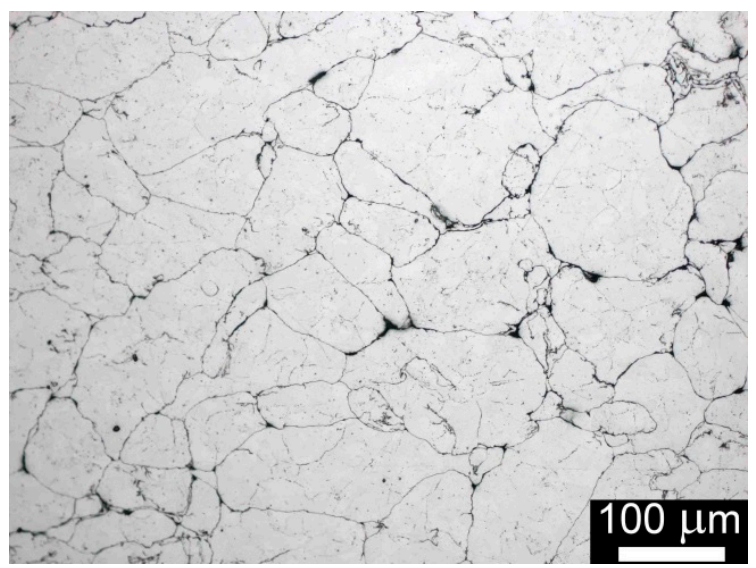

(a)

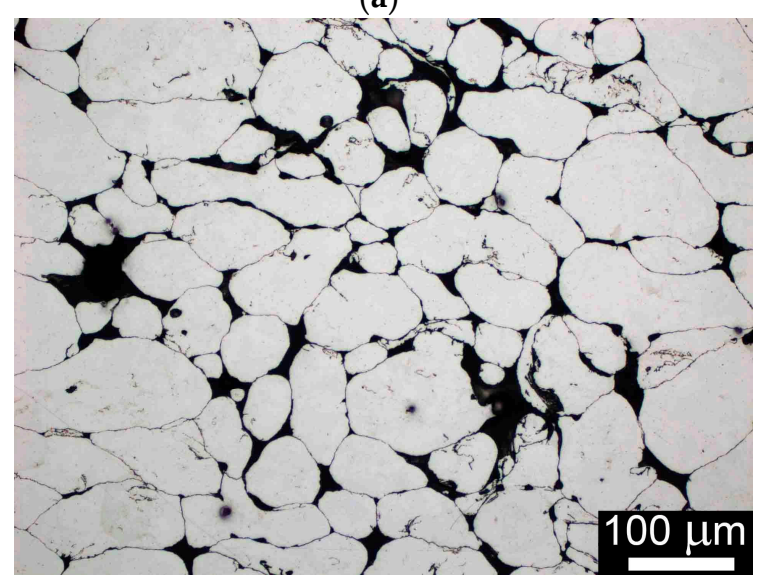

(c)

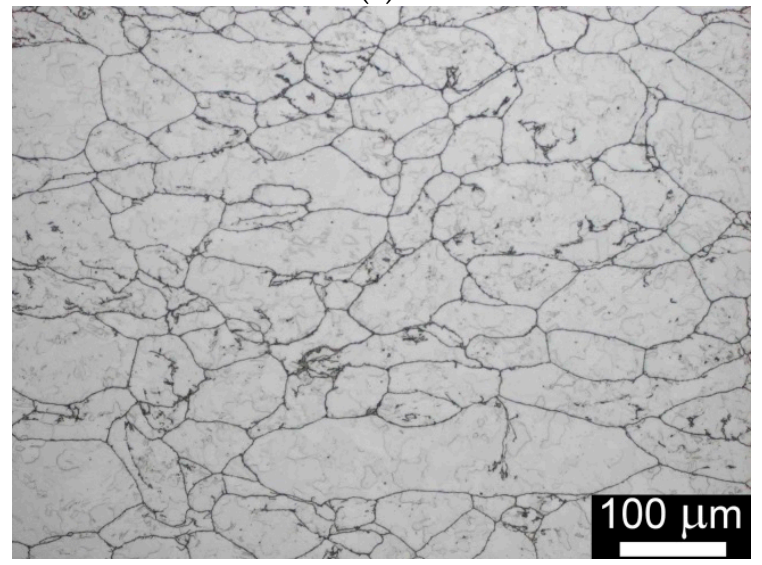

(e)

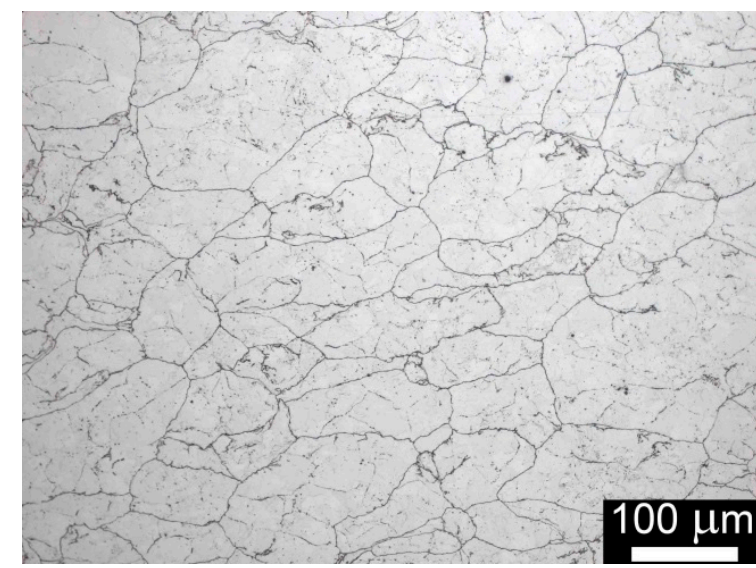

(b)

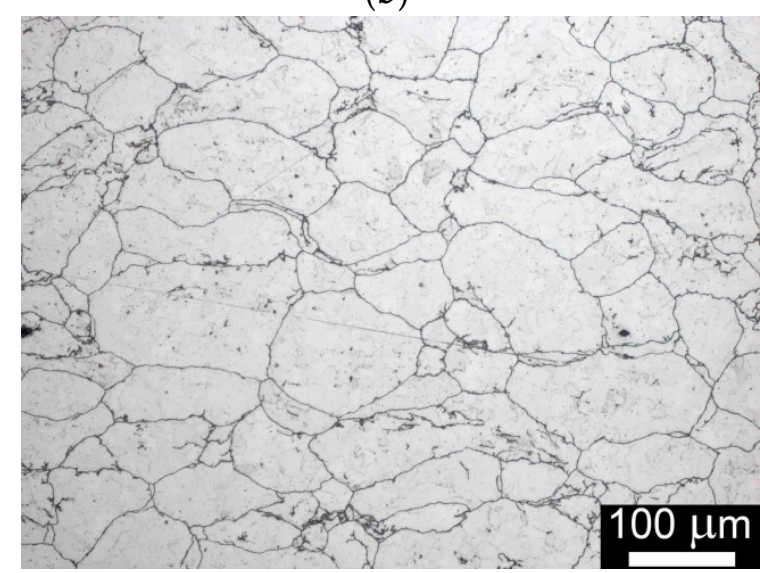

(d)

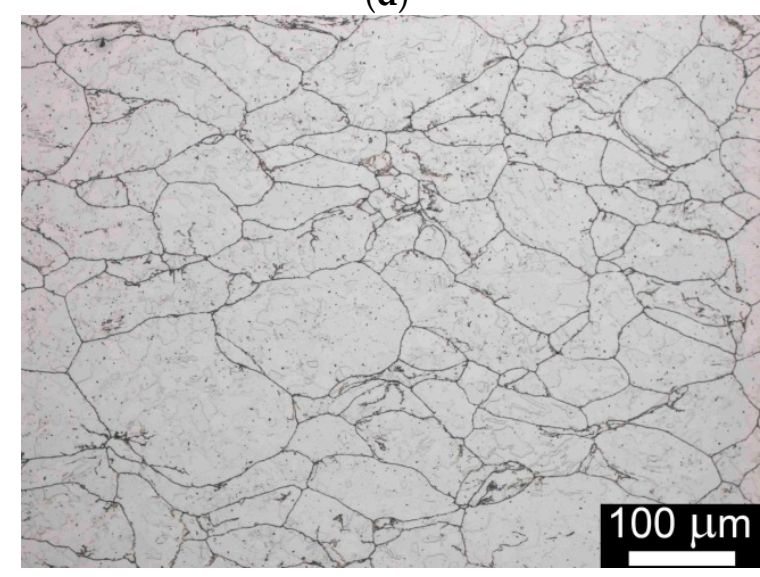

(f)

Figure 3. Microstructure of materials prepared from Zn150 powder, etched with 5\% Nital, OM: (a) $100 \mathrm{MPa}$, CP; (b) $500 \mathrm{MPa}, \mathrm{CP}$; (c) $100 \mathrm{MPa}, \mathrm{CP}-\mathrm{S}$; (d) $500 \mathrm{MPa}, \mathrm{CP}-\mathrm{S}$; (e) $100 \mathrm{MPa}$, HP; (f) $500 \mathrm{MPa}, \mathrm{HP}$. 
The values of microhardness of prepared materials were in the range from 40-49 HV025 for Zn7.5 powder and from 40-45 HV025 for Zn150 powder. No significant dependence on compacting pressure or processing method was found.

\subsection{3-Point Bend Test}

The plots representing the evolution of the flexural strength and the maximal displacement before the failure are shown in Figure 4. In some cases, no data are plotted due to the low handling strength of prepared samples or very low obtained values (impossible to determine).

In the case of materials prepared from Zn7.5 powder, there is a clear increasing dependence of flexural strength on the applied compacting pressure. The same tendency of materials prepared from Zn150 powder processed by CP and CP-S can be observed. The different behavior appears only in the case of $\mathrm{Zn} 150$ powder HP material where the value of the flexural strength of material processed under 100 and $200 \mathrm{MPa}$ is around $200 \mathrm{MPa}$, and then, the value decreased to approximately $150 \mathrm{MPa}$ for compacting pressures of 300 and $400 \mathrm{MPa}$. Material pressed under $500 \mathrm{MPa}$ reaches the value of about $200 \mathrm{MPa}$ again. Generally, CP and CP-S materials prepared from Zn150 powder have higher flexural strength values than materials from Zn7.5 powder prepared with the same method at the same compacting pressures. In the case of materials prepared under compacting pressure of $500 \mathrm{MPa}$ from Zn7.5 powder, the flexural strength increases from $20 \mathrm{MPa}$ for $\mathrm{CP}$ to $76 \mathrm{MPa}$ for CP-S material. The flexural strength of materials prepared from Zn150 powder under the same condition increases from $88 \mathrm{MPa}$ for CP to $148 \mathrm{MPa}$ for CP-S material.

The values of the flexural strength of materials prepared by HP are substantially higher when compared to the CP-S and CP materials, especially in the case of materials prepared from $\mathrm{Zn} 7.5$ powder. The highest value of flexural strength $(322 \mathrm{MPa})$ is reached with material prepared by HP under compacting pressure of $400 \mathrm{MPa}$. While in the case of material from Zn7.5 powder, a significant increase of flexural strength is observed for all the applied compacting pressures due to the HP processing (Figure 4a), in the case of Zn150 powder material, no such significant increase of flexural strength is observed, and in the case of compacting pressure of $400 \mathrm{MPa}$, the values of flexural strength for CP-S and HP material are similar (Figure 4b).

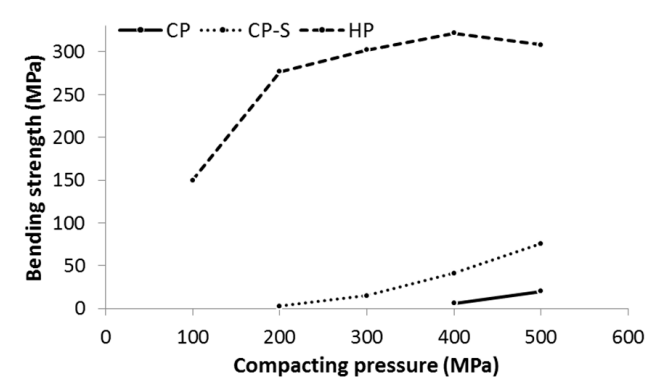

(a)

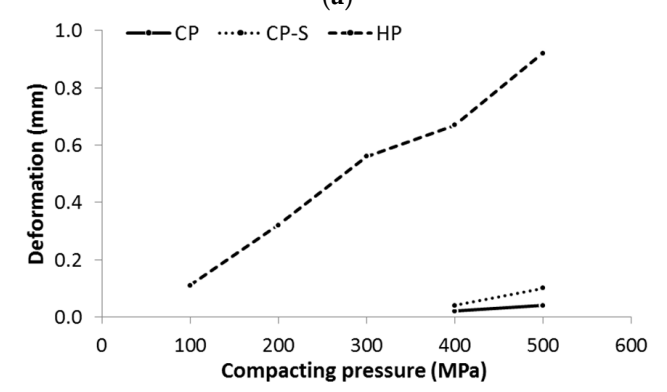

(c)

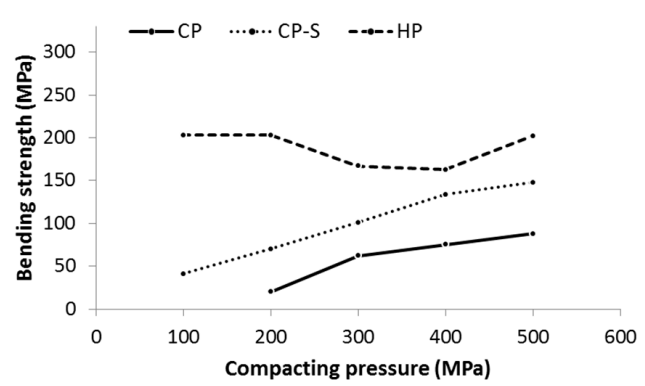

(b)

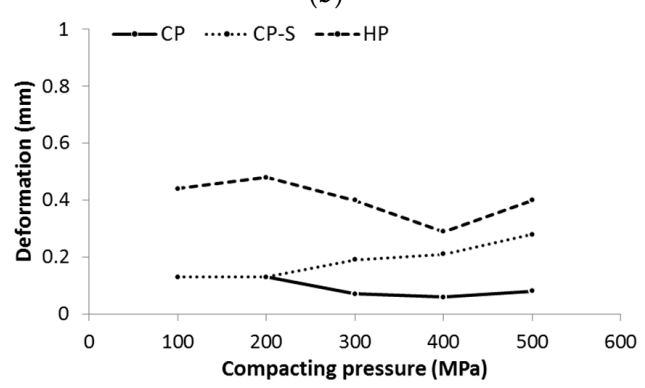

(d)

Figure 4. Dependence of flexural strength and displacement on compacting pressure and processing of prepared materials: (a) Flexural strength, Zn7.5 powder; (b) Flexural strength, Zn150 powder; (c) Displacement, Zn7.5 powder; (d) Displacement, Zn150 powder. 
The displacement before the failure of Zn7.5 powder materials prepared by CP and by CP-S is very low (from 0.04-0.10 mm for $500 \mathrm{MPa}$ compacting pressure) (Figure 4c). However, in the case of HP Zn7.5 powder materials, the displacement before the failure lies in the range from $0.11 \mathrm{~mm}$ for the lowest compacting pressure up to $0.92 \mathrm{~mm}$ for the pressure of $500 \mathrm{MPa}$.

The results of maximal displacement before the failure of materials prepared from Zn150 powder (Figure $4 \mathrm{~d}$ ) are relatively steady around the value of $0.2 \mathrm{~mm}$ for CP and CP-S materials and around $0.4 \mathrm{~mm}$ for HP materials. In the case of HP Zn150 powder material, the values of displacement before failure decrease from $0.49 \mathrm{~mm}$ to $0.29 \mathrm{~mm}$ for materials compacted under $200 \mathrm{MPa}$ and $400 \mathrm{MPa}$, respectively (equivalent to the change of flexural strength) and then again increases for material pressed under $500 \mathrm{MPa}$ (Figure 4d).

\subsection{Fractographic Analysis}

The samples broken during the three-point bend testing were examined with the aim to analyze the fracture mechanism and its correlation with the samples' processing in terms of SEM. Details of fracture surfaces of materials prepared from Zn7.5 powder are shown in Figure 5. Only samples prepared under the lowest and the highest compacting pressures (as possible) with adequate processing were analyzed. The fracture surface of CP material is characterized by crack growth along powder particle boundaries, which is also the case for the material compacted under $200 \mathrm{MPa}$ and sintered at $400{ }^{\circ} \mathrm{C}$ (Figure $5 \mathrm{a}-\mathrm{c}$ ). The fracture mechanism can be considered as transgranular. There is visible porosity between individual powder particles in the case of CP materials and CP-S materials compacted under $200 \mathrm{MPa}$. The fracture surface of material pressed under $500 \mathrm{MPa}$ and then sintered shows lower porosity compared to the previous material states. In addition, crack growth through particle boundaries is accompanied by powder particle cracking (Figure 5d). The combination of transgranular with more pronounced intergranular fracture is characteristic for HP materials. Broken powder particles are characterized by plane facet or by fine non-well developed cleavage facets with a river-like morphology. HP resulted also in the decrease of a number of pores present on the samples' fracture surface, while no visible pores are present on the fracture surface of HP material compacted under $500 \mathrm{MPa}$ (Figure 5f) (showing also the detail of the fracture mechanism).

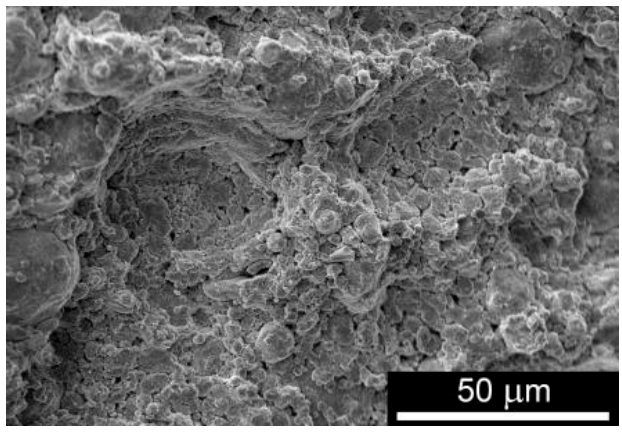

(a)

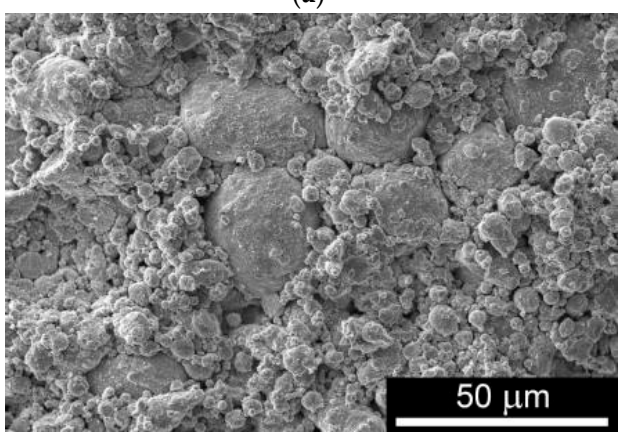

(c)

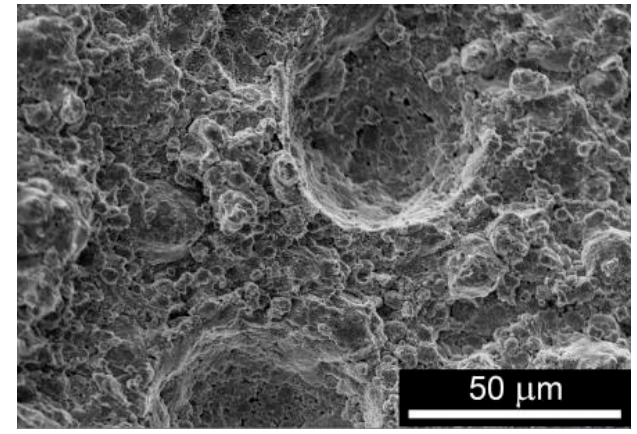

(b)

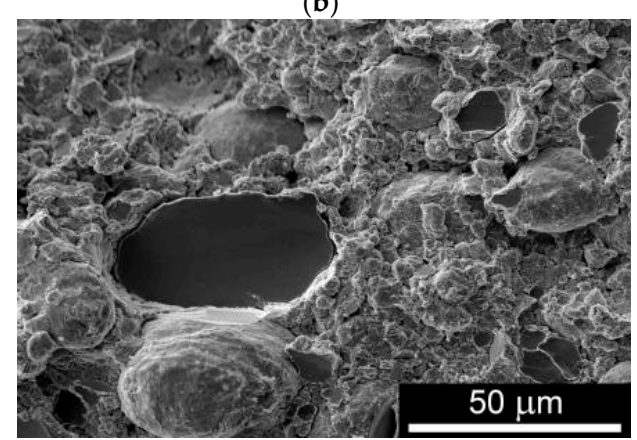

(d)

Figure 5. Cont. 


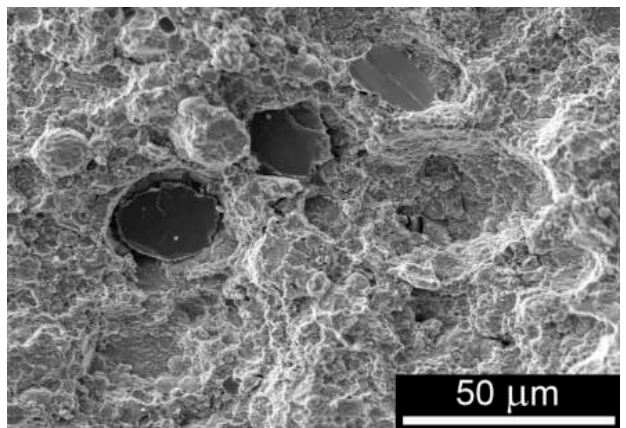

(e)

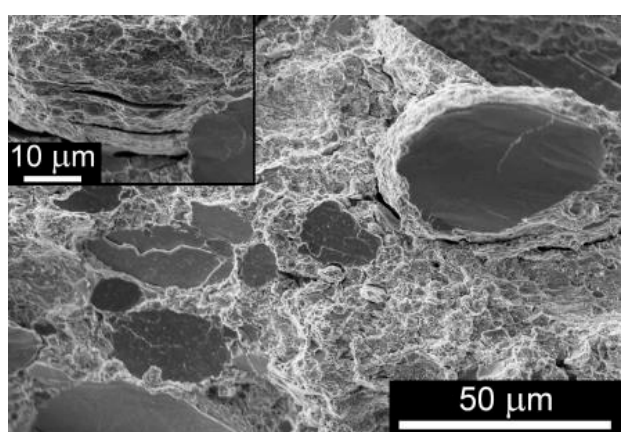

(f)

Figure 5. Microstructure of materials prepared from Zn7.5 powder, SEM: (a) $400 \mathrm{MPa}, \mathrm{CP}$; (b) $500 \mathrm{MPa}$, CP; (c) $200 \mathrm{MPa}, \mathrm{CP}-\mathrm{S}$; (d) $500 \mathrm{MPa}, \mathrm{CP}-\mathrm{S}$; (e) $100 \mathrm{MPa}, \mathrm{HP}$; (f) $500 \mathrm{MPa}, \mathrm{HP}$.

In Figure 6, a summary of the details of the fracture surfaces of materials prepared from Zn150 powder is shown. Compared with materials prepared from Zn7.5 powder, in the case of Zn150 powder materials, there is a visibly higher influence of compacting pressure on particles' deformation and porosity. In the case of CP materials, the particles are deformed and mechanically bonded (Figure 6a,b). Three-point bend test loading led to particles being pulled out of the structure, while holes remaining on the fracture surface can be seen instead of missing particles in Figure 6a. Similarly to the Zn7.5 powder materials, the transgranular fracture mechanism is characteristic for CP and CP-S samples compacted under $200 \mathrm{MPa}$ (Figure $6 \mathrm{a}-\mathrm{c}$ ). The combination of transgranular with intergranular fracture is characteristic for CP-S compacted under $500 \mathrm{MPa}$ and HP materials (Figure 6d-f). Well-developed cleavage facets with the river-like morphology can be observed on fracture surfaces (broken powder particles) of HP materials (Figure 6e,f), showing also the detail of the fracture mechanism in Figure $6 f$.

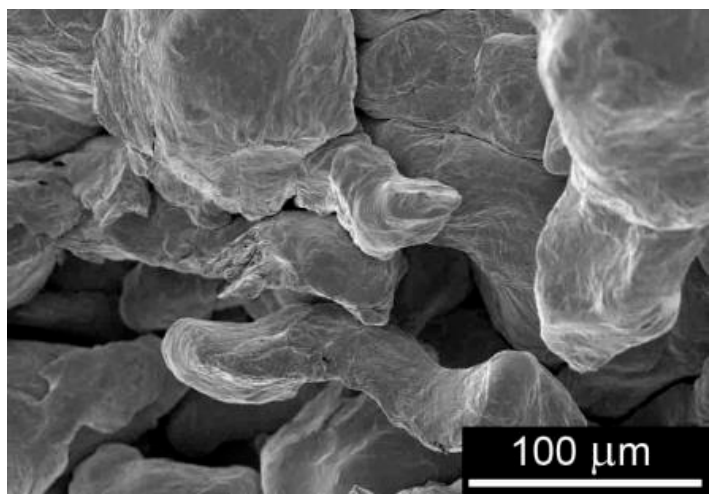

(a)

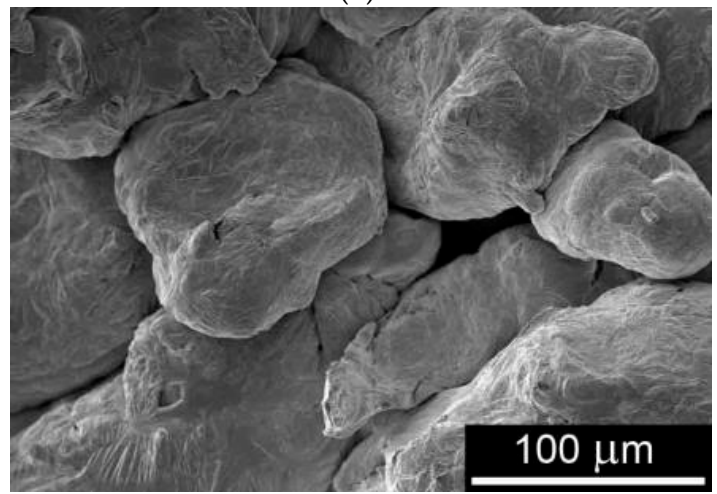

(c)

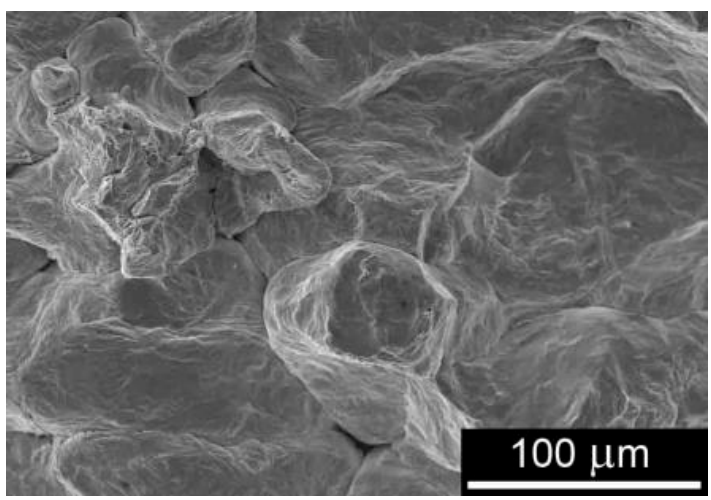

(b)

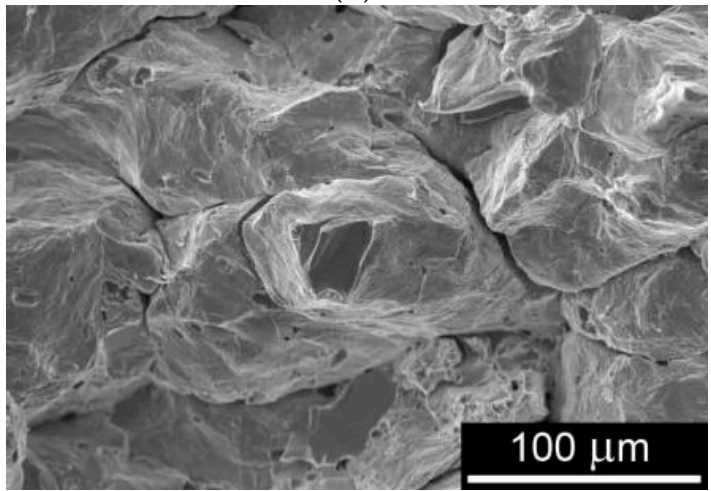

(d)

Figure 6. Cont. 


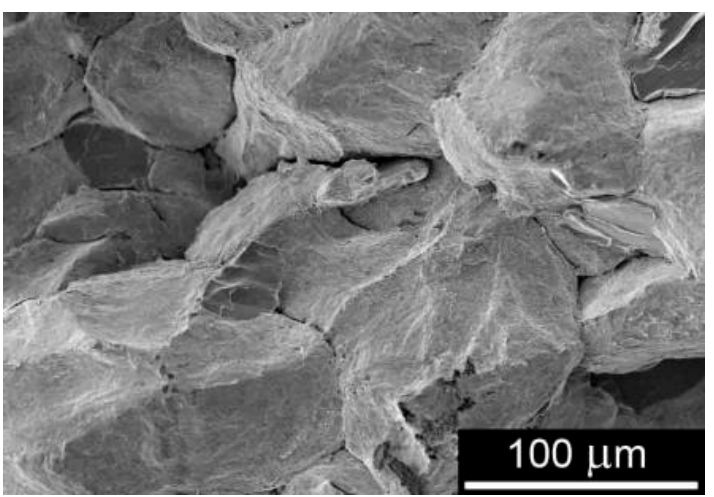

(e)

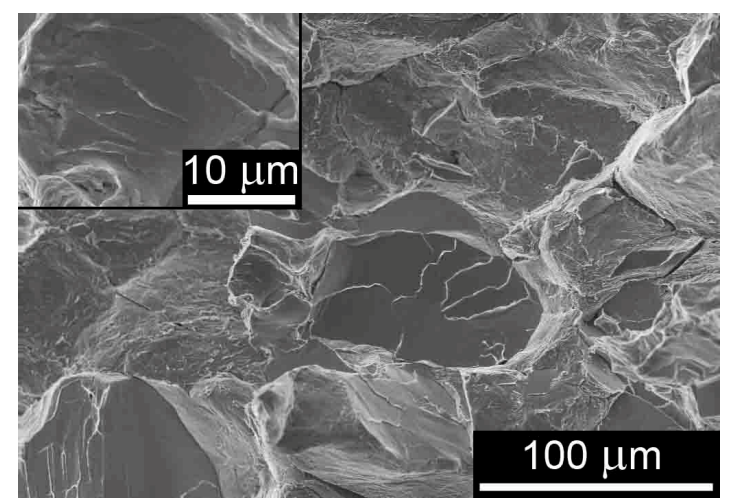

(f)

Figure 6. Microstructure of materials prepared from Zn150 powder, SEM: (a) $200 \mathrm{MPa}, \mathrm{CP}$; (b) $500 \mathrm{MPa}$, CP; (c) $100 \mathrm{MPa}, \mathrm{CP}-\mathrm{S}$; (d) $500 \mathrm{MPa}, \mathrm{CP}-\mathrm{S}$; (e) $100 \mathrm{MPa}, \mathrm{HP}$; (f) $500 \mathrm{MPa}, \mathrm{HP}$.

\section{Discussion}

Microstructural analysis of materials prepared from Zn7.5 powder (Figure 2) revealed lower deformability of powder particles when compared to Zn150 powder particles (Figure 3). The considerably lower particle size and spherical shape of Zn7.5 powder may be the reason for this behavior.

Even though the mechanical properties of pure zinc powder particles are comparable, the size of the particles plays a similar role as in the case of grain size. The larger size of the particles was connected with their higher deformability during the processing, and the lower particle size resulted in grain boundaries' (particles boundaries) strengthening of material. The strengthening of material was also connected with lower deformability of the material.

The deformability of individual powder particles influenced the material properties and content of porosity. Although the zinc particles were not significantly deformed in some of the cases (mostly Zn7.5, Figure 2), the porosity of all the prepared materials decreased with increasing compacting pressure and even decreased with the application of temperature during the material processing (CP-S and HP). This fact can be attributed to a wide distribution of powder particle size, when the space between large particles was filled up with the smaller ones. However, the porosity of materials from Zn7.5 powder was substantially higher than in the case of material prepared from Zn150 powder, which can be also observed from the fractographic evaluation of broken samples (Figures 5 and 6). This can be explained by the larger range of the powder particle size measured for Zn150 powder (up to $640 \mu \mathrm{m}$ ) compared to Zn7.5 powder (up to $20 \mu \mathrm{m}$ ) and the adequate arrangement of the particles with different size in the compacted sample volume.

CP-S processing of Zn7.5 powder materials did not influence the material microstructure with as much intensity as the increasing compression pressure did. Only the minor effect of the following sintering of CP materials was observed by metallographic analysis (Figure 2). In the case of Zn150 powder materials, the following sintering of CP samples led to the increase of the porosity of materials prepared at low pressures (Figure 3c). Due to the high sintering temperature of $400{ }^{\circ} \mathrm{C}$ and high material porosity (of CP samples), the powder particles reduced the surface energy and changed their shape from irregular rod-shaped to spherical during sintering. At the same time, no dimensional changes of prepared samples were observed, which would generally correspond if a solid-state diffusion was the primary sintering mechanism [34]. The shape changes of particles and no shrinkage could lead to pores growing between the particles.

The effect of HP processing is more evident on the Zn7.5 powder-based materials when compared to the Zn150 powder materials. Elevated temperature during the material processing resulted in improved plasticity and enhanced deformability of fine powder particles (Zn7.5 powder). The particles' deformation is observable on materials' microstructures documented in Figure 2e,f. Elevated temperature applied during material processing resulted in activation of more slip systems 
in the hexagonal close packed (HCP) structure (also characteristic for zinc) [34]. In the case of Zn150 powder materials, the elevated temperature of the processing had no evident influence on material microstructure. In the case of smaller powder particles, the improved deformability of the material due to the activation of more slip systems was much more significant compared to the larger powder particles, which were deformable even at room temperature. Quite good deformability of large powder particles was not significantly improved and remained the same as in the case of CP and CP-S materials from the microstructural point of view, Figure 3.

There is only a small number of articles dealing with evaluation of the mechanical properties of pure zinc [17,25-28]. From the mechanical properties point of view, materials in these studies were characterized mostly by Vickers hardness and tensile tests. The Vickers hardness of experimental materials prepared from Zn7.5 and Zn150 powders in the presented work was determined as 40-49 HV025 and 40-45 HV025, respectively. The values were higher in comparison to the cast pure zinc of $30 \mathrm{HV}$ given in [17]; however, the values were comparable with results of Vickers hardness testing of hot extruded pure zinc of $44 \mathrm{HV} 5$ given in [27]. Due to the obtained microstructure of materials prepared by powder metallurgy, the characteristic mechanical properties should correlate more with the properties of wrought materials than with cast materials. Considering the powder particles' boundaries as grain boundaries, the microstructure of the materials processed from Zn7.5 powder (knowing the real particle size was up to $20 \mu \mathrm{m}$ ) is comparable with the fine recrystallized equi-axed grains with an average grain size of $20 \mu \mathrm{m}$ characteristic for pure extruded zinc analyzed in [27].

The resistance of prepared powder-based materials against the fracture during the three-point bend test was (besides particles deformability) influenced mainly by the mechanical interlocking of irregularities on the powder particle surfaces, which was promoted by plastic deformation during the pressing. The bonding of particles was responsible for the mechanism of the bulk material fracture. Because of the spherical shape of Zn7.5 powder particles, the flexural strength of compacted samples showed lower values when compared to materials prepared from Zn150 powder. Larger surface area and particles shape of Zn150 powder particles allowed easier contact of particles and interlocking of the surface irregularities, which was even enhanced by the particles' larger deformability compared to the Zn7.5 powders, which was easily observed in the case of CP and CP-S materials, Figure 3.

The surface layer of corrosion products on particles' surface had also a negative influence on powder particles' compaction during sintering and HP (processes performed at elevated temperature, enhancing diffusion processes). Only the diffusion mechanisms contributed to sintering of particles in the case of the absence of an external pressure [35]. The oxide layer on the powder particles could affect the diffusion bonding of particles during sintering, and this can be seen in the case of CP-S Zn150 powder material compacted under $100 \mathrm{MPa}$ (Figure 3c). In this case, the observed porosity was higher than as in the case of CP materials. Due to the surface oxide layer on the powder particles, the sintering process could be affected by the diffusion delay. The role of the surface oxide layer in the sintering of metal powder particles was defined as follows: Shifting the mechanisms of the sintering process from a bulk-transport mechanism to that controlled by surface transport [34]. Even though the content of oxygen was detected to be higher on the Zn7.5 powder particles, the powder particles' low deformability seemed to have a larger influence on material compaction than the oxide layer on the powder particles. Due to the low particle deformability and spherical shape, only limited areas of individual particles were in direct contact, and the conditions for diffusion were worse compared to the larger and more plane particles of Zn150 powder material. However, according to the experimental observations, the influence of the oxide layer on the sinterability of zinc was minimal, and the presence of an oxide layer on powder particles makes essentially no difference in the kinetics of sintering [34].

Even though the influence of processing parameters on Zn powder-based materials' microstructure is minimal, the influence of the processing on the samples' bending properties was observed. CP-S materials reached higher values of flexural strength for both powder particles sizes compared to the CP materials. The influence was, however, only minor compared to the influence of the HP. 
In the case of Zn7.5 powder material, the CP samples prepared under 100, 200 and $300 \mathrm{MPa}$ did not reach the required handling strength necessary for three-point bend testing, and only samples prepared under 400 and $500 \mathrm{MPa}$ were tested. However, the values reached for the flexural strength and displacement before fracture were very low (Figure $4 \mathrm{a}, \mathrm{c}$ ), which corresponds to low particle deformation and the subsequent low bonding and high porosity of the material (Figure 2a,b). The transgranular fracture mechanism and porosity present on the fracture surfaces support this theory (Figure 5a,b). Sintering of the Zn7.5 powder material resulted in higher material handling strength; however, the values of flexural strength reached were still low for materials prepared under 100-300 MPa (Figure 4a). The fracture surface of the CP-S sample prepared under $200 \mathrm{MPa}$ corresponded to the microstructural observation and low bending characteristics of the material reached (Figure 5c). Sintering materials prepared under higher pressures resulted in flexural strength values higher than $40 \mathrm{MPa}$ (41 and $76 \mathrm{MPa}$ for 400 and $500 \mathrm{MPa}$ pressure, respectively). However, the displacement before the fracture was still very low and comparable to the one of CP samples prepared under the same pressures (Figure 4c). HP of Zn7.5 powder materials resulted in a significant increase of materials' flexural strength, reaching maximal value of $322 \mathrm{MPa}$ for material prepared under $400 \mathrm{MPa}$ (Figure 4a). The positive influence of compacting pressure of HP-processed Zn7.5 powder material was revealed by three-point bend test up to the compacting pressure of $400 \mathrm{MPa}$. Samples prepared under $500 \mathrm{MPa}$ reached lower values of flexural strength than the maximum, which can be connected with the limited deformability of the material due to the HCP crystallographic structure of zinc [36]. High compaction of the material during HP under $500 \mathrm{MPa}$ resulted in strong particle bonding, limiting the transgranular fracture mechanism. With increasing compacting pressure, a larger amount of broken powder particles can be observed on the samples' fracture surfaces (Figure 5e,f). The cleavage mechanism playing a role in the material failure was responsible for the measured decrease of the flexural strength (HP material processed under $500 \mathrm{MPa}$ ); however, displacement before fracture still increased.

In the case of Zn150 powder materials, only the sample prepared by CP under $100 \mathrm{MPa}$ did not reach the adequate handling strength necessary for the three-point bend test. Due to the higher deformability of larger powder particles compared to the Zn7.5 powder materials, CP and CP-S samples reached higher values of flexural strength and displacement before fracture when compared to the Zn7.5 samples. In the case of CP-S Zn150 powder materials, sintering had a significantly positive influence on material bending properties (improvement of flexural strength approximately twice compared to the CP materials). HP Zn150 powder materials reached even larger values of bending properties than the CP-S materials; however, the improvement was not as significant as in the case of Zn7.5 powder materials (Figure 4). The differences between the CP-S and HP Zn150 powder materials are significant for materials prepared under 100-300 MPa; however, only a minor influence was observed in the case of materials prepared under 400 and $500 \mathrm{MPa}$ (Figure 4). This corresponds to the microstructural observations, where only a minor influence on the materials microstructure applying higher pressure (400-500 MPa) and temperature during HP was observed (Figure 3). The bonding of particles of materials prepared under 300-500 MPa was comparable for CP-S and HP materials. HP Zn150 powder materials' fracture surfaces were similar for all of the applied pressures during the preparation of materials, while differences in the CP-S materials' fracture surfaces were observed (Small pressures during materials processing resulted in intergranular failure, while the combination of inter- and trans-granular fracture correlated with higher compacting pressures (Figure 6)).

Detailed fractographic analysis of the fracture surfaces of HP processed materials revealed the mechanism of crack propagation (Figures $5 \mathrm{f}$ and $6 \mathrm{f}$ ). Due to the tensile loading, microcracks through individual powder particles were observed, characteristic of the cleavage facets in Figures $5 \mathrm{f}$ and $6 \mathrm{f}$. The final crack responsible for the sample's failure followed the powder particles' boundaries connecting cleavage facets (cracked particles). 


\section{Conclusions}

Pure zinc materials prepared by methods of powder metallurgy were examined from the microstructural and mechanical properties point of view. Bulk materials from zinc powder of a mean particles size of 7.5 and $150 \mu \mathrm{m}$ were prepared with three preparation methods: Cold pressing $(\mathrm{CP})$, cold pressing followed by sintering (CP-S) and hot pressing (HP). The obtained results show the following:

(1) The deformability of zinc powder substantially depends on the size and shape of the powder particles. Smaller spherical particles of Zn7.5 were observed to be only slightly deformable at room temperature (CP), whereas large irregularly-shaped particles of Zn150 powder showed good deformability resulting in low porosity of samples and good material compaction. The addition of sintering (CP-S) and HP improved the deformability of the Zn7.5 powder; however, no significant influence was observed in the case of Zn150 powder.

(2) The increase of compacting pressure was connected with the increase of the bending characteristics of prepared Zn powder materials.

(3) The flexural strength of CP Zn150 powder materials was substantially higher when compared to materials prepared from Zn7.5 powder. Low deformability of small-sized powder particles led to the poor mechanical interlocking and low flexural strength of materials prepared from Zn7.5 powder compacted at room temperature.

(4) CP-S of $\mathrm{Zn}$ powder-based materials led to the significant improvement of the bending characteristics of prepared materials. The maximal values of the flexural strength were measured for CP-S materials prepared under $500 \mathrm{MPa}$; $76 \mathrm{MPa}$ for Zn7.5 powder and $148 \mathrm{MPa}$ for Zn150 powder materials.

(5) HP resulted in even more pronounced improvement of the bending characteristics of $\mathrm{Zn}$ powder-based materials. The highest value reached of the flexural strength were measured for Zn7.5 material prepared under 400 MPa (322 MPa) and for Zn150 material prepared under 100 and $200 \mathrm{MPa}(203 \mathrm{MPa})$.

(6) The intercrystalline fracture mechanism was characteristic for CP materials prepared under all of the applied pressures and CP-S materials prepared under pressures from 100-400 MPa. The combination of inter- and trans-crystalline fracture mechanisms was characteristic for CP-S materials prepared under $500 \mathrm{MPa}$ and for HP materials.

Acknowledgments: This work was supported by Project No. LO1211, Materials Research Centre and by Project No. LO1202, Center of New Technologies for Mechanical Engineering (NETME), plus the projects of the Ministry of Education, Youth and Sports of the Czech Republic under the "National sustainability program". We are also grateful to Pavla Puškášová and Jakub Puškáš for the professional English editing service.

Author Contributions: Pavel Doležal conceived of and designed the experiments. Michaela Krystýnová and Matěj Březina performed the experiments. Pavel Doležal, Michaela Krystýnová, Stanislava Fintová and Matěj Březina analyzed the data. Pavel Doležal, Josef Zapletal and Jaromír Wasserbauer contributed reagents/materials/analysis tools. Michaela Krystýnová and Stanislava Fintová wrote the paper.

Conflicts of Interest: The authors declare no conflict of interest.

\section{References}

1. Witte, F.; Hort, N.; Vogt, C.; Cohen, S.; Kainer, K.U.; Willumeit, R.; Feyerabend, F. Degradable biomaterials based on magnesium corrosion. Curr. Opin. Solid State Mater. Sci. 2008, 12, 63-72. [CrossRef]

2. Tan, L.; Yu, X.; Wan, P.; Yang, K. Biodegradable Materials for Bone Repairs: A Review. J. Mater. Sci. Technol. 2013, 29, 503-513. [CrossRef]

3. Staiger, M.P.; Pietak, A.M.; Huadmai, J.; Dias, G. Magnesium and its alloys as orthopedic biomaterials: A review. Biomaterials 2006, 27, 1728-1734. [CrossRef] [PubMed]

4. Heublein, B.; Rohde, R.; Kaese, V.; Niemeyer, M.; Hartung, W.; Haverich, A. Biocorrosion of magnesium alloys: A new principle in cardiovascular implant technology? Heart 2003, 89, 651-656. [CrossRef] [PubMed] 
5. Waksman, R.; Pakala, R.; Kuchulakanti, P.K.; Baffour, R.; Hellinga, D.; Seabron, R.; Tio, F.O.; Wittchow, E.; Hartwig, S.; Harder, C.; et al. Safety and efficacy of bioabsorbable magnesium alloy stents in porcine coronary arteries. Catheter. Cardiovasc. Interv. 2006, 68, 607-617. [CrossRef] [PubMed]

6. Shuai, C.; Zhou, Y.; Yang, Y.; Feng, P.; Liu, L.; He, C.; Zhao, M.; Yang, S.; Gao, C.; Wu, P. Biodegradation Resistance and Bioactivity of Hydroxyapatite Enhanced Mg-Zn Composites via Selective Laser Melting. Materials 2017, 10, 307. [CrossRef] [PubMed]

7. Chen, J.; Wu, P.; Wang, Q.; Yang, Y.; Peng, S.; Zhou, Y.; Shuai, C.; Deng, Y. Influence of Alloying Treatment and Rapid Solidification on the Degradation Behavior and Mechanical Properties of Mg. Metals 2016, 6, 259. [CrossRef]

8. He, C.; Bin, S.; Wu, P.; Gao, C.; Feng, P.; Yang, Y.; Liu, L.; Zhou, Y.; Zhao, M.; Yang, S.; et al. Microstructure Evolution and Biodegradation Behavior of Laser Rapid Solidified Mg-Al-Zn Alloy. Metals 2017, 7, 105. [CrossRef]

9. Gu, X.; Zheng, Y.; Cheng, Y.; Zhong, S.; Xi, T. In vitro corrosion and biocompatibility of binary magnesium alloys. Biomaterials 2009, 30, 484-498. [CrossRef] [PubMed]

10. Ilich, J.Z.; Kerstetter, J.E. Nutrition in Bone Health Revisited: A Story beyond Calcium. J. Am. Coll. Nutr. 2000, 19, 715-737. [CrossRef] [PubMed]

11. Xu, L.; Yu, G.; Zhang, E.; Pan, F.; Yang, K. In vivo corrosion behavior of Mg-Mn-Zn alloy for bone implant application. J. Biomed. Mater. Res. Part A 2007, 83, 703-711. [CrossRef] [PubMed]

12. Hänzi, A.C.; Gerber, I.; Schinhammer, M.; Löffler, J.F.; Uggowitzer, P.J. On the in vitro and in vivo degradation performance and biological response of new biodegradable $\mathrm{Mg}-\mathrm{Y}-\mathrm{Zn}$ alloys. Acta Biomater. 2010, 6, 1824-1833. [CrossRef] [PubMed]

13. Zhang, E.; Yin, D.; Xu, L.; Yang, L.; Yang, K. Microstructure, mechanical and corrosion properties and biocompatibility of Mg-Zn-Mn alloys for biomedical application. Mater. Sci. Eng. C 2009, 29, 987-993. [CrossRef]

14. Li, Z.; Gu, X.; Lou, S.; Zheng, Y. The development of binary Mg-Ca alloys for use as biodegradable materials within bone. Biomaterials 2008, 29, 1329-1344. [CrossRef] [PubMed]

15. Gu, X.; Zheng, Y.; Zhong, S.; Xi, T.; Wang, J.; Wang, W. Corrosion of, and cellular responses to Mg-Zn-Ca bulk metallic glasses. Biomaterials 2010, 31, 1093-1103. [CrossRef] [PubMed]

16. Zhang, S.; Zhang, X.; Zhao, C.; Li, J.; Song, Y.; Xie, C.; Tao, H.; Zhang, Y.; He, Y.; Jiang, Y. Research on an $\mathrm{Mg}-\mathrm{Zn}$ alloy as a degradable biomaterial. Acta Biomater. 2010, 6, 626-640. [CrossRef] [PubMed]

17. Vojtěch, D.; Kubásek, J.; Šerák, J.; Novák, P. Mechanical and corrosion properties of newly developed biodegradable Zn-based alloys for bone fixation. Acta Biomater. 2011, 7, 3515-3522. [CrossRef] [PubMed]

18. Tapiero, H.; Tew, K.D. Trace elements in human physiology and pathology: Zinc and metallothioneins. Biomed. Pharmacother. 2003, 57, 399-411. [CrossRef]

19. Aggett, P.J.; Harries, J.T. Current status of zinc in health and disease states. Arch. Dis. Child. 1979, 54, 909-917. [CrossRef] [PubMed]

20. Fosmire, G.J. Zinc toxicity. Am. J. Clin. Nutr. 1990, 51, 225-227. [PubMed]

21. Bowen, P.K.; Drelich, J.; Goldman, J. Zinc Exhibits Ideal Physiological Corrosion Behavior for Bioabsorbable Stents. Adv. Mater. 2013, 25, 2577-2582. [CrossRef] [PubMed]

22. Wang, Y.; Wei, M.; Gao, J.; Hu, J.; Zhang, Y. Corrosion process of pure magnesium in simulated body fluid. Mater. Lett. 2008, 62, 2181-2184. [CrossRef]

23. Ollig, J.; Kloubert, V.; Weßels, I.; Haase, H.; Rink, L. Parameters Influencing Zinc in Experimental Systems in Vivo and in Vitro. Metals 2016, 6, 71. [CrossRef]

24. Kirkland, N.T.; Lespagnol, J.; Birbilis, N.; Staiger, M.P. A survey of bio-corrosion rates of magnesium alloys. Corros. Sci. 2010, 52, 287-291. [CrossRef]

25. ASM International. ASM Handbook, 10th ed.; ASM International: Materials Park, OH, USA, 2004.

26. Brandes, E.A.; Brook, G.B.; Smithells, C.J. Smithells Metals Reference Book, 7th ed.; Brandes, E.A., Brook, G.B., Eds.; Butterworth-Heinemann: Boston, MA, USA, 1998; Volume 22, p. 94.

27. Kubásek, J.; Vojtěch, D.; Jablonská, E.; Pospíšilová, I.; Lipov, J.; Ruml, T. Structure, mechanical characteristics and in vitro degradation, cytotoxicity, genotoxicity and mutagenicity of novel biodegradable $\mathrm{Zn}-\mathrm{Mg}$ alloys. Mater. Sci. Eng. C 2016, 58, 24-35. [CrossRef] [PubMed]

28. Sikora-Jasinska, M.; Mostaed, E.; Mostaed, A.; Beanland, R.; Mantovani, D.; Vedani, M. Fabrication, mechanical properties and in vitro degradation behavior of newly developed $\mathrm{Zn}$ Ag alloys for degradable implant applications. Mater. Sci. Eng. C 2017, 77, 1170-1181. [CrossRef] [PubMed] 
29. Wang, X.; Lu, H.M.; Li, X.L.; Li, L.; Zheng, Y.F. Effect of cooling rate and composition on microstructures and properties of Zn-Mg alloys. Trans. Nonferrous Met. Soc. China 2007, 17, 122-125.

30. Bowen, P.K.; Seitz, J.M.; Guillory, R.J.; Braykovich, J.P.; Zhao, S.; Goldman, J.; Drelich, J.W. Evaluation of wrought $\mathrm{Zn}-\mathrm{Al}$ alloys $(1,3$, and $5 \mathrm{wt} \% \mathrm{Al})$ through mechanical and in vivo testing for stent applications. J. Biomed. Mater. Res. Part B Appl. Biomater. 2017. [CrossRef] [PubMed]

31. Demirtas, M.; Purcek, G.; Yanar, H.; Zhang, Z.J.; Zhang, Z.F. Effect of chemical composition and grain size on RT superplasticity of Zn-Al alloys processed by ECAP. Lett. Mater. 2015, 5, 328-334. [CrossRef]

32. Shaw, C.A.; Tomljenovic, L. Aluminum in the central nervous system (CNS): Toxicity in humans and animals, vaccine adjuvants, and autoimmunity. Immunol. Res. 2013, 56, 304-316. [CrossRef] [PubMed]

33. Baba, K.; Hatada, R.; Flege, S.; Ensinger, W.; Shibata, Y.; Nakashima, J.; Sawase, T.; Morimura, T. Preparation and antibacterial properties of Ag-containing diamond-like carbon films prepared by a combination of magnetron sputtering and plasma source ion implantation. Vacuum 2013, 89, 179-184. [CrossRef]

34. Munir, Z.A. Analytical treatment of the role of surface oxide layers in the sintering of metals. J. Mater. Sci. 1979, 14, 2733-2740. [CrossRef]

35. Nassef, A.; El-Garaihy, W.; El-Hadek, M. Mechanical and Corrosion Behavior of Al-Zn-Cr Family Alloys. Metals 2017, 7, 171. [CrossRef]

36. Prasad, Y.V.R.K.; Sasidhara, S. Hot Working Guide: A Compendium of Processing Maps; ASM International: Materials Park, OH, USA, 1997; p. 496.

(C) 2017 by the authors. Licensee MDPI, Basel, Switzerland. This article is an open access article distributed under the terms and conditions of the Creative Commons Attribution (CC BY) license (http://creativecommons.org/licenses/by/4.0/). 